Thorax (1965), 20, 505.

\title{
Hypoxaemia after aortic valve surgery under cardiopulmonary bypass
}

\author{
R. M. M. FOR D H A M ${ }^{1}$ \\ From the National Heart Hospital, Westmoreland Street, London, W.1
}

It has been known for many years that arterial hypoxaemia occurs after thoracic surgery, even following minimal interference with the lungs (Maier and Cournand, 1943 ; Björk and Hilty, 1954 ; DiBenedetto, Glass, Siebens, and Klopstock, 1963) and after non-thoracic operations (Nunn and Payne, 1962). It is also a known sequel of open cardiac surgery (Hedley-Whyte, Corning, Laver, Austen, and Bendixen, 1965), and especially if severe cardiorespiratory complications occur (Sandison, McCormick, and Sykes, 1963). This paper describes a pattern of hypoxaemia after aortic valve surgery under cardiopulmonary bypass, and its mechanism is discussed.

\section{MATERIAL}

Eighteen patients who had undergone aortic valve surgery under cardiopulmonary bypass were studied. Of these, nine had aortic homografts, five had valve decalcifications, two had aortic StarrEdwards valve replacements, one had a commissurotomy, and one had subvalvar aortic stenosis relieved. All had lone aortic valve disease of varying severity, and some had had episodes of left ventricular failure in the past. A median sternotomy incision was used (Gerbode, Braimbridge, and Melrose, 1958) and full-flow, normothermic bypass was maintained with a Guy's-Ross heart-lung apparatus, the bypass time varying between 39 and 154 minutes (mean 80 minutes). Plasma haemoglobin levels at the conclusion of bypass varied between 10 and $80 \mathrm{mg} . / 100 \mathrm{ml}$. (mean $32 \mathrm{mg}$. $/ 100 \mathrm{ml}$.). The lungs were regularly inflated during bypass at a rate of $10 /$ minute with a tidal volume of $200 \mathrm{ml}$. using a $50 \%$ mixture of nitrous oxide and oxygen, and they were hyperinflated at irregular intervals during this time and throughout the whole operation. Post-operatively, the patients were allowed to breathe spontaneously, and deep breathing every 15 minutes was encouraged. Coughing and physiotherapy was

${ }^{1}$ Present address: Department of Anaesthetics, St. Thomas' Hospital, London, S.E.1 commenced soon after arrival in the recovery room.

Twelve of the patients had no major postoperative complications, although all but one developed radiological changes in the lungs consisting of patchy shadowing in one or both lower zones, sometimes extending up into the middle zones, usually associated with clinical signs of bronchial breathing and fine and medium rales over the affected areas. These radiological changes were occasionally associated with those of collapse of lobar or segmental distribution, and the radiographs also demonstrated the inability of these patients to take a really deep breath post-operatively. Two patients developed left basal effusions. All patients had a cough with increased sputum after operation, which was sometimes purulent.

One patient had respiratory difficulty and bronchospasm for 24 hours after operation, two developed obvious pulmonary oedema on the second day, and three developed cardio-respiratory failure on the first, second, and third days respectively. If a patient required artificial ventilation, or was considered too ill to be taken off oxygen, the study was discontinued.

\section{METHOD}

A pre-operative arterial blood sample was analysed in all but two cases, and post-operative studies were made within three to six hours of operation (day ' $O$ ') and then on successive days for up to one week. All patients had breathed room air for at least $7 \mathrm{~min}$. before $4 \mathrm{ml}$. samples were withdrawn into siliconeoil lubricated glass syringes in which the dead space had been filled with heparin solution $(10 \mathrm{mg} . / \mathrm{ml}$.). Arterial samples were obtained by needle puncture of the brachial or femoral artery, and simultaneous venous samples either from a nylon catheter with its tip in the right atrium or from a fine polyethylene catheter ('P.E.50') placed in the pulmonary artery (five cases). No right atrial catheter was accepted unless its tip had been felt in the right atrium during operation, or else it had entered the right ventricle and then been withdrawn just into the atrium. In three cases in which a catheter was also present in the left atrium, oxygenated blood was withdrawn through this. 
The $p \mathrm{H}$ and $\mathrm{PCO}_{2}$ values in the blood were measured using the interpolation method of Siggaard Andersen, Engel, Jørgensen, and Astrup (1960), and $\mathrm{Po}_{2}$ values with a Radiometer (E 5044) oxygen electrode and oxygen monitor. All $\mathrm{Po}_{2}$ values are expressed at a temperature of $37^{\circ} \mathrm{C}$. and the $p \mathrm{H}$ of the sample concerned. No corrections were made for changes in barometric pressure. A sample was taken for haemoglobin estimation at each study.

The alveolar $\mathrm{Po}_{2}$ was calculated from the equation:

$$
\mathrm{PAO}_{2}=\mathrm{PlO}_{2}-\mathrm{PaCO}_{2}\left[\mathrm{FIO}_{2}+\frac{1}{\mathrm{R}} \underset{\mathrm{FIO}}{\mathrm{FiO}_{2}}\right]
$$

assuming that alveolar and arterial $\mathrm{PCO}_{2}$ values were identical. This assumption will introduce a small error into the estimated $\mathrm{PAO}_{2}$ of the order of $2 \mathrm{~mm}$. $\mathrm{Hg}$ in the presence of a $28 \%$ venous admixture effect (by calculation). The respiratory exchange ratio (R) was taken as 0.76 (Sturridge, Theye, Fowler, and Kirklin, 1964). A deviation in the actual respiratory exchange ratio of 0.1 above the assumed value would lead to an error of approximately $4 \mathrm{~mm} . \mathrm{Hg}$ in the calculated alveolar oxygen pressure. The oxygen capacity of haemoglobin was assumed to be $1.34 \mathrm{ml}$./ g., and the solubility coefficient of oxygen in whole blood to be 0.0031 vol. $\% / \mathrm{mm}$. Hg Po. The oxygen saturation of haemoglobin was calculated from the data of Dill (Dittmer and Grebe, 1958), and the venous admixture calculated by the method of Finley, Lenfant, Haab, Piiper, and Rahn (1960), the $p H$ of pulmonary capillary blood being taken as identical to that of arterial blood.

In those patients in whom a left atrial catheter was present, pressure measurements were made using the right atrium as a reference point, and in those in whom venous admixture was calculated when breathing a high oxygen concentration, $100 \%$ oxygen was inhaled through a non-return valve (Siebe-Gorman), with a mouthpiece and noseclip, for at least $10 \mathrm{~min}$. before sampling. A more extended period of oxygen breathing was found to cause many patients to become distressed.

\section{RESULTS}

The overall results are shown in Table $I$ and Figures 1 and 2. Mean $\mathrm{PaO}_{2}$ values fell to 56 and $57 \mathrm{~mm}$. Hg on the first and second days postoperatively and then began to rise. Mean values on the second day for $\mathrm{A}-\mathrm{aDo}_{2}(52 \mathrm{~mm}$. $\mathrm{Hg})$ and venous admixture $(28 \cdot 2 \%$ of cardiac output) were furthest from normal at this time, subsequently improving, although the $\mathrm{A}-\mathrm{aDO}_{2}$ and the $\mathrm{PaO}_{2}$ were still abnormal after one week. The proportion of venous admixture on the second day, which could not be compensated for by breathing $100 \%$ oxygen, was $59 \%$ (Table II). The mean $\mathrm{PaCO}_{2}$ was found to decrease to a value of $32 \mathrm{~mm}$. $\mathrm{Hg}$ on the third day, and then to rise to within normal
TABLE I

OVERALL RESULTS

\begin{tabular}{|c|c|c|c|c|c|c|c|c|}
\hline Day & $\begin{array}{l}\text { Pre- } \\
\text { op. }\end{array}$ & 0 & 1 & 2 & 3 & 4 & 5 & $7 \underset{8}{7}$ and \\
\hline No. of studies & 16 & 16 & 14 & 13 & 13 & 8 & 8 & 5 \\
\hline $\begin{array}{r}\text { Mean } \mathrm{PAO}_{2} \\
(\mathrm{~mm} . \mathrm{Hg})\end{array}$ & 102 & 101 & 104 & 109 & 111 & 107 & 108 & 102 \\
\hline $\begin{array}{l}\text { Mean } \mathrm{PaO}_{2} \\
(\mathrm{~mm} . \mathrm{Hg})\end{array}$ & $\begin{array}{c}87 \\
(10 \cdot 5)\end{array}$ & $\begin{array}{c}64 \\
(11 \cdot 0)\end{array}$ & $\begin{array}{c}56 \\
(10 \cdot 1)\end{array}$ & $\begin{array}{c}57 \\
(6.8)\end{array}$ & $\begin{array}{c}62 \\
(6 \cdot 7)\end{array}$ & $\begin{array}{c}64 \\
(6 \cdot 0)\end{array}$ & $\begin{array}{c}68 \\
(3 \cdot 3)\end{array}$ & $\begin{array}{c}67 \\
(7 \cdot 3)\end{array}$ \\
\hline $\begin{array}{c}\mathrm{Mean} \mathrm{A-aDo} \\
(\mathrm{mm} \cdot \mathrm{Hg})\end{array}$ & & & & & $\begin{array}{c}49 \\
(9 \cdot 5)\end{array}$ & $\begin{array}{c}43 \\
(11 \cdot 2)\end{array}$ & $\begin{array}{c}40 \\
(6 \cdot 6)\end{array}$ & $\begin{array}{c}35 \\
(9 \cdot 1)\end{array}$ \\
\hline $\begin{array}{c}\text { Mean } \mathrm{PaCO}_{2} \\
(\mathrm{~mm} \cdot \mathrm{Hg})\end{array}$ & $\begin{array}{c}38 \\
(4 \cdot 6)\end{array}$ & $\begin{array}{c}37 \\
(4.9)\end{array}$ & $\begin{array}{c}36 \\
(4 \cdot 6) \\
\end{array}$ & $\begin{array}{c}33 \\
(3 \cdot 8)\end{array}$ & $\left(\begin{array}{c}32 \\
(3 \cdot 0)\end{array}\right.$ & $\begin{array}{c}34 \\
(4 \cdot 6)\end{array}$ & $\begin{array}{c}35 \\
(5 \cdot 6) \\
\end{array}$ & $\begin{array}{r}37 \\
(4 \cdot 3)\end{array}$ \\
\hline \multicolumn{2}{|c|}{ No. of studies } & 12 & 11 & 7 & 4 & & & \\
\hline \multirow{2}{*}{\multicolumn{2}{|c|}{$\begin{array}{l}\text { Mean venous } \\
\text { admixture (\%) } \\
\text { Mean A-V O. diff. } \\
\text { (vol. \%) }\end{array}$}} & $\begin{array}{l}16 \cdot 5 \\
(5 \cdot 0)\end{array}$ & $\mid \begin{array}{c}23.5 \\
(10.6)\end{array}$ & $\begin{array}{l}28 \cdot 2 \\
(7 \cdot 0)\end{array}$ & $\begin{array}{l}25 \cdot 2 \\
(4 \cdot 7)\end{array}$ & & & \\
\hline & & $5 \cdot 7$ & 5.9 & $5 \cdot 4$ & $5 \cdot 2$ & & & \\
\hline \multicolumn{2}{|c|}{ Mean $\mathrm{P}_{\bar{v} \mathrm{O}_{2}}(\mathrm{~mm} . \mathrm{Hg})$} & 32 & 31 & 30 & 32 & & & \\
\hline
\end{tabular}

Figures in parentheses indicate the standard deviation.

T ABLE II

VENOUS ADMIXTURE BREATHING AIR AND $100 \%$ OXYGEN

\begin{tabular}{|c|c|}
\hline & $\begin{array}{l}\text { Mean Venous } \\
\text { Admixture }(\%)\end{array}$ \\
\hline $\begin{array}{l}\text { Breathing air } \\
\text { Breathing } 100 \% \mathrm{O}_{2} \ldots\end{array}$ & $\begin{array}{l}26 \cdot 7 \\
15 \cdot 7\end{array}$ \\
\hline
\end{tabular}

Second day; seven patients.

limits after one week. On only three occasions did the $\mathrm{PaCO}_{2}$ rise above $45 \mathrm{~mm}$. $\mathrm{Hg}$, all on the evening after operation, the values being $46,45 \cdot 5$, and $48.5 \mathrm{~mm}$. $\mathrm{Hg}$ respectively. In seven cases the mean $\mathrm{PaCO}_{2}$ value on the second day when breathing air was $34 \mathrm{~mm}$. $\mathrm{Hg}$ (mean $\mathrm{PaO}_{2}=54 \mathrm{~mm}$. $\mathrm{Hg}$ ), and when breathing oxygen was $35 \mathrm{~mm}$. $\mathrm{Hg}$ (mean $\mathrm{PaO}_{2}=230 \mathrm{~mm}$. Hg). The mean partial pressure of oxygen in the mixed venous blood changed little over the first three days, although it was consistently low. The mean arterio-venous oxygen difference was greatest on the day of operation and the following day $(5.7$ and 5.9 vol. $\%$ respectively) and fell to $5 \cdot 2$ vol. \% on the third day.

No correlation was found between the severity of hypoxaemia and the duration of bypass, nor with plasma haemoglobin levels at the end of perfusion. However, in comparing the degree of hypoxaemia with the age of the patient, it was found that in those patients aged 30 to 39 years the lung changes on the second and third postoperative days were significantly less than in those of 50 to 59 years of age $(P<0.05)$. In the three patients in whom left atrial pressure was measured, no relation was found between the amount of venous admixture and the level of the mean left atrial pressure. As the mean left atrial pressure was raised by transfusion (minimum $13 \mathrm{~mm}$. $\mathrm{Hg}$, up to a maximum of $28 \mathrm{~mm}$. $\mathbf{H g}$ ) the venous admixture in one patient rose and then 


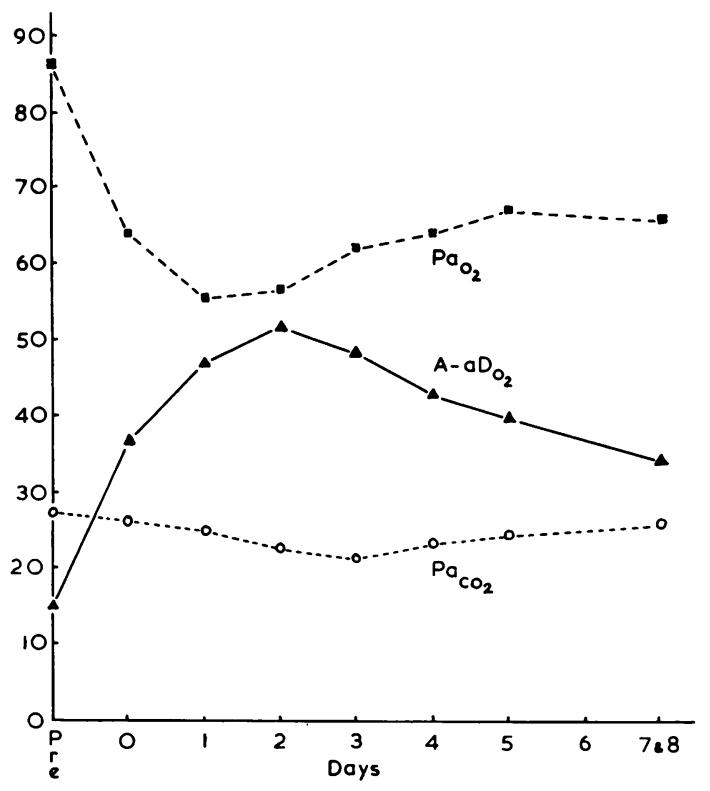

FIG. 1. Changes in $\mathrm{PaO}_{2}, \mathrm{~A}-a \mathrm{Do}_{2}$ and $\mathrm{PaCO}_{2}(\mathrm{~mm}$. $\mathrm{Hg}$ ) for one week following operation.

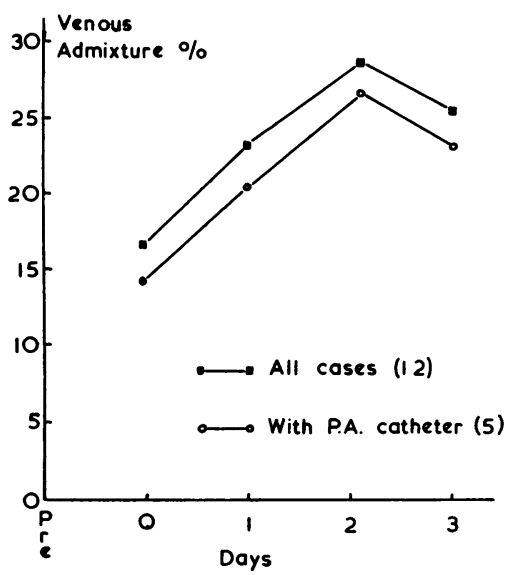

PIG. 2.Changes in venous admixture following operation.

fell again, in another fell progressively, and in the third rose. No overall changes in venous admixture exceeded $5 \%$ of the cardiac output.

\section{DISCUSSION}

The changes in oxygen transport through the lungs in the patients in this series showed a pattern, becoming worse until the second post- operative day and then beginning to improve toward normal, although the mean $\mathrm{A}-\mathrm{aDo}_{2}$ was still more than twice the pre-operative value after one week. An increase in respiratory equivalent ventilation ( $\mathrm{ml} . / \mathrm{min}$.)

oxygen uptake (ml./min.) was found during the early post-operative period by Sturridge $e t$ al. (1964), which was greatest on the second day, a pattern similar to the one found in this series. The changes in this series were also more severe than those found to occur after other types of cardiac surgery without bypass. In a series of 10 closed cardiac operations (nine mitral valvotomies and one patent ductus) the mean $\mathrm{A}-\mathrm{aDo}_{2}$ values on the evening of operation and on the following two days were 22,24 , and $26 \mathrm{~mm}$. $\mathrm{Hg}$ respectively. This compares with values of 37,48 , and $52 \mathrm{~mm}$. $\mathrm{Hg}$ in the present series, the difference between the two series being significant on the first and second days $(P<0.01$ and $P<0.02)$ but not on the evening of operation $(P>0.05)$. Hypoxaemia also occurred whether clinically obvious pulmonary complications followed operation or not, although in patients who developed severe pulmonary complications the arterial hypoxaemia was much more severe.

The cause of the hypoxaemia was shown to be due to a large increase in venous admixture, and only on three occasions could overall hypoventilation, with a raised $\mathrm{PaCO}_{2}$, be demonstrated. On the contrary, when the hypoxaemia was at its most severe, the mean $\mathrm{PaCO}_{2}$ values were decreased to 32 to $34 \mathrm{~mm}$. $\mathrm{Hg}$, indicating overall hyperventilation. This did not appear to be a response to hypoxaemia, since raising the arterial oxygen content did not raise the mean $\mathrm{PaCO}_{2}$ significantly. Osborn, Popper, Kerth, and Gerbode (1962) also found that a rise in $\mathrm{PaCO}_{2}$ was uncommon after cardiopulmonary bypass, although they demonstrated an alveolar-arterial gradient for $\mathrm{PCO}_{2}$, indicating alterations in ventilation-perfusion relationships.

The possible causes of an increased $\mathrm{A}-\mathrm{aDo}_{2}$ are a diffusion defect, anatomical right-to-left shunts, and uneven ventilation-perfusion relationships.

DIFFUSION This factor has been investigated using carbon monoxide uptake and shows a decrease in the early post-operative period of 25 to $40 \%$ below pre-operative values (Schramel, Cameron, Ziskind, Adam, and Creech, 1959), lasting up to 14 days. Ellison, Yeh, Maretz, and Ellison (1963) found that the decrease in carbon monoxide uptake was greater after operation 
under bypass than after thoracotomy alone. However, in the presence of uneven distribution of gases within the lungs, the carbon monoxide uptake is reduced by this factor alone, and in patients with a diagnosis of 'alveolar-capillary block syndrome' Finley, Swenson, and Comroe (1962) showed that the arterial hypoxaemia could be accounted for solely on the basis of uneven distribution of ventilation in relation to blood flow. A diffusion defect is thought to have a significant effect in producing an $\mathrm{A}-\mathrm{aDo}_{2}$ only when the $\mathrm{PAO}_{2}$ is well below normal (Farhi and Rahn, 1955), which was not the case in this series. It appears, therefore, that a primary diffusion defect, if present, plays only a small part in postperfusion hypoxaemia.

ANATOMICAL SHUNTS No right-to-left shunts other than those found in normal circumstances were present in these patients before operation, and these have been shown to contribute only a small part to venous admixture (Björk, Malmström, and Uggla, 1954; Cheng, 1964). The investigational methods used are unable to distinguish between (a) an anatomical shunt and (b) pulmonary venous admixture due to complete airway closure, as both still contribute to the $\mathrm{A}-\mathrm{aDo}_{2}$ during $100 \%$ oxygen breathing. The anatomical shunt through bronchial, pleural, and Thebesian vessels is normally approximately $2 \%$ of the cardiac output (Aviado, Daly, Lee, and Schmidt, 1961), and it appears unlikely that these could increase to the high values found post-operatively in this series. A mechanism based on alveolar atelectasis seems much more probable.

UNEVEN VENTILATION-PERFUSION RELATIONS Changes in ventilation-perfusion relations may produce hypoxaemia without hypercarbia. Areas of lung in which alveolar ventilation falls in relation to perfusion will cause arterial hypoxaemia in spite of compensating hyperventilation of other parts of the lung, due to the shape of the oxygen dissociation curve. The ventilation-perfusion ratio can be lowered by either hypoventilation or non-ventilation of areas of lung compared to perfusion, or by an increase in perfusion compared to ventilation. By giving subjects $100 \%$ oxygen to breathe, any hypoxaemia due to relative hypoventilation or to diffusion will be compensated for, leaving only the completely non-ventilated areas still contributing to venous admixture. In this series $59 \%$ of the total venous admixture was not compensated for by $100 \%$ oxygen, indicating that much of the hypoxaemia is due to complete airway closure, while main- taining blood flow through the non-ventilated areas. The remaining $41 \%$ is probably due to relative hypoventilation and uneven distribution of ventilation, although evidence here is contradictory. Schramel et al. (1959) found an increase कै in physiological dead space post-operatively, but $\vec{\circ}$ Howatt, Talner, Sloan, and DeMuth (1962) found that intrapulmonary gas mixing was normal, using the seven-minute nitrogen washout test. In the present series the increased cough with $\times$ sputum, often purulent and copious, after opera- No tion would certainly lead to variable airway resistance and therefore to uneven distribution of ventilation, although no measurements were made to substantiate this.

In patients with long-standing aortic valve disease the left ventricular myocardium becomes abnormal, and left ventricular failure may occur after surgery, leading to pulmonary oedema and hypoxaemia. In those patients with left atrial catheters in place the results tentatively indicate $\vec{\bullet}$ that left ventricular failure did not contribute to of hypoxaemia, since altering the mean left atrial pressure produced no consistent change in venous admixture. However, in the two patients who developed pulmonary oedema on the second day, the $\mathrm{A}-\mathrm{aDo} \mathrm{D}_{2}$ had risen to the usual levels at this time but then failed to fall towards normal until the left ventricular failure had been controlled. It appears, therefore, that the left atrial pressure has little effect on venous admixture unless obvious pulmonary oedema occurs. Further work is in progress on the relation between left atrial pressure and venous admixture in these circumstances.

In the presence of a high venous admixture the oxygen content of mixed venous blood becomes important in reference to arterial hypoxaemia in $₹$ that the lower is the venous oxygen the lower will $\mathrm{o}$ be the $\mathrm{PaO}_{2}$ for a given venous admixture effect, and in patients with combined cardio-respiratory failure very low levels of $\mathrm{PaO}_{2}$ are seen in spite of breathing $100 \%$ oxygen. In this series the mean $\mathcal{N}$ mixed venous $\mathrm{Po}_{2}$ was consistently low at 30 to $32 \mathrm{~N}$ $\mathrm{mm}$. $\mathrm{Hg}$ (corresponding to a saturation of about $60 \%$ ) for the first three days, although the arteriovenous oxygen difference was lowest on the day after operation, thereafter improving. The steady $\stackrel{0}{\overparen{D}}$ values for mixed venous $\mathrm{Po}_{2}$ appear to be due to a balance between changes in cardiac output and arterial hypoxaemia of pulmonary origin.

In view of the arterial hypoxaemia which occurs after open aortic valve surgery it is suggested that $\bar{\nabla}$ oxygen therapy should be continued for at least five days post-operatively, even in those patients 
who appear to be progressing well, and for longer periods if pulmonary complications occur.

\section{SUMMARY}

Oxygen transport through the lungs was investigated in 18 patients following aortic valve surgery under cardiopulmonary bypass in whom no severe cardiac or respiratory complications occurred. Arterial hypoxaemia was found to occur, which was maximal on the second post-operative day and which lasted for more than one week. This has been found to be due to an increase in venous admixture up to a mean value of $28.2 \%$ on the second post-operative day, and $59 \%$ of this was found to result from complete airway closure while maintaining blood flow to the affected areas. The remaining $41 \%$ was probably due to uneven distribution of ventilation.

I wish to thank Mr. D. N. Ross for allowing me to investigate his patients, and Dr. Eunice Lockey, Dr. S. J. G. Semple, and Dr. K. Saunders for their help and advice.

\section{REFERENCES}

Aviado, D. M., Daly, M. de Burgh, Lee, C. Y., and Schmidt, C. F. (1961). The contribution of the bronchial circulation to the venous admixture in pulmonary venous blood. J. Physiol. (Lond.), 155,602 .

Björk, V. O., and Hilty, H. J. (1954). The arterial oxygen and carbon dioxide tension during the postoperative period in cases of pulmonary resections and thoracoplasties. J. thorac. Surg., 27, 455.

- Malmström, G., and Uggla, L-G. (1954). Comparison of the oxygen tension in blood from the left atrium and systemic artery. Amer. Heart J., 48, 8.
Cheng, T. O. (1964). Alveolar-arterial oxygen tension gradient. Circulation, 30, Suppl. no. 3, p. 59.

DiBenedetto, A., Glass, P., Siebens, A. A., and Klopstock, R. (1963). The effects of limited pulmonary resection on ventilationperfusion relationships in the postoperative period. J. thorac. cardiovasc. Surg., 45, 312.

Dittmer, D., and Grebe, R. M. (1958). Handbook of Respiration, p. 73. - Saunders, Philadelphia.

Ellison, L. T., Yeh, T. J., Maretz, W. H., and Ellison, R. G. (1963). Pulmonary diffusion studies in patients undergoing nonthoracic, thoracic, and cardiopulmonary bypass procedures. Ann Surg., $157,327$.

Farhi, L. E., and Rahn, H. (1955). A theoretical analysis of the alveolar-arterial $\mathrm{O}_{2}$ difference with special reference to the distribution effect. J. appl. Physiol., 7, 699.

Finley, T. N., Lenfant, C., Haab, P., Piiper, J., and Rahn, H. (1960). Venous admixture in the pulmonary circulation of unesthetized dogs. Ibid., 15, 418.

Swenson, E. W., and Comroe, J. H. (1962). The cause of arterial hypoxaemia at rest in patients with "alveolar-capillary block syndrome". J. clin. Invest., 41, 618.

Gerbode, F., Braimbridge, M. V., and Melrose, D. G. (1958). Median sternotomy for open cardiac surgery during total heart-lung bypass. Arch. Surg., 76, 821.

Hedley-Whyte, J., Corning, H., Laver, M. B., Austen, W. G., and Bendixen, H.H. (1965). Pulmonary ventilation-perfusion relations after heart valve replacement or repair in man.J. clin. Invest., 44, 406.

Howatt, W. F., Talner, N. S., Sloan, H., and DeMuth, G. R. (1962). Pulmonary function changes following repair of heart lesions with the aid of extracorporeal circulation. J. thorac. cardiovasc. Surg., 43, 649.

Maier, H. C., and Cournand, A. (1943). Studies of the arterial oxygen saturation in the postoperative period after pulmonary resection. Surgery, 13, 199.

Nunn, J. F., and Payne, J. P. (1962). Hypoxaemia after general anaesthesia. Lancet, 2,631 .

Osborn, J. J., Popper, R. W., Kerth, W. J., and Gerbode, F. (1962). Respiratory insufficiency following open heart surgery. Ann. Surg., 156, 638.

Sandison, J. W., McCormick, P. W., and Sykes, M. K. (1963)i Intermittent positive pressure respiration after open-heart surgery. Brit. J. Anaesth., 35, 100.

Schramel, R. J., Cameron, R., Ziskind, M., Adam, N., and Creech, O. (1959). Studies of pulmonary diffusion after open heart surgery. J. thorac. cardiovasc. Surg., 38, 281.

Siggaard Andersen, O., Engel, K., Jørgensen, K., and Astrup, P. (1960). A micro method for determination of $\mathrm{pH}$, carbon dioxide tension, base excess and standard bicarbonate in capillary blood. Scand. J. clin. Lab. Invest., 12, 172.

Sturridge, M. F., Theye, R. A., Fowler, W. S., and Kirklin, J. W. (1964). Basal metabolic rate after cardiovascular surgery. $J$. thorac. cardiovasc. Surg., 47, 298. 